\title{
A familial form of convulsive disorder with or without mental retardation limited to females: extension of a pedigree limits possible genetic mechanisms
}

\author{
KeITH FABISIAK' AND ROBERT P. ERICKSON ${ }^{1,2}$ \\ Departments of 'Pediatrics and Communicable Diseases and ${ }^{2}$ Human Genetics, University of \\ Michigan School of Medicine, Ann Arbor, Michigan, USA
}

\begin{abstract}
An unusual pedigree of female-limited seizures with or without mental retardation is updated. The disorder was first detected in a large cohort of women whose fathers were brothers, and affected women had previously transmitted the disorder. Four brothers of affected females have now had five unaffected daughters while four affected women have had four affected and one unaffected daughters and two unaffected sons. This unusual transmission pattern is discussed in terms of germ-line imprinting, neuronal sexual differentiation, and the generally higher risk of seizures seen when the mothei, rather than the father, is affected.
\end{abstract}

Received 22 January, revised 23 April, accepted for publication 24 April 1990

Key words: epilepsy; female-limited mental retardation; seizures; sex-limited gene expression; sexual differentiation of brain.

Juberg \& Hellman reported an unusual pedigree of sex-limited inheritance in 1971. Fifteen females related as sisters, or as first cousins through their fathers, had a similar convulsive disorder, sometimes associated with mental retardation. At the time of that report, two affected females had had single affected daughters but none of the males had reproduced. We recently re-ascertained this pedigree when an affected girl from the fifth generation presented for care. Brothers of the affected women of generation IV have now had five unaffected daughters. This unusual pattern of inheritance of female-limited, hereditary disease could possibly be explained by: 1) X-linkage of a variably penetrant and sex-limited trait, 2) sex-limited autosomal (or pseudoautosomal) dominant inheritance, or 3 ) germ line imprinting (reviewed in Erickson 1985, Monk 1988). Sexual differentiation of the brain (reviewed in Goy \& McEwen 1980) could be responsible for sex limitation. The pedigree is also discussed in relation to the higher risk of seizures in offspring of mothers than of fathers with epilepsy (Ottman et al. 1988).

\section{Case History}

A two-and-one-half-year-old female was seen for evaluation of seizures, self-injurious and destructive behavior, and progressive cognitive decline (V 14 in Fig. 1). Her birth and immediate neonatal course were unremarkable. At 3 months of age she had onset of generalized, tonic-clonic seizures. At 5 months of age phenobarbital therapy was initiated. Over the first 2 years of life seiz- 
ures were noted to occur approximately every 6 weeks. Her development over that same period of time was felt to be normal.

At 2 years of age a period of severe seizure activity lasting $30 \mathrm{~min}$ occurred. Over the ensuing 6 months her parents noted a progressive decline in speech, memory, and gross motor skills. She now walks on her toe tips and runs in a peculiar posture with her hands and arms flexed, whereas her gait was previously normal. In addition to generalized tonic-clonic seizures, she has been having petit mal seizures and Jacksonian seizures followed by postictal hemiparesis up to three or four times a week.

Physical exam exhibited a well-nourished, agitated and uncooperative girl prone to outbursts. She was noted during the exam to have several episodes of staring with decreased activity lasting 15 to $30 \mathrm{~s}$ each. Her weight, height, and head circumference were all appropriate for age. There was no evident dysmorphism. There was normal muscle tone noted throughout. She appeared to use both sides of her body equally and drew using her left hand. Reflexes were $3+$ in the upper and lower extremities bilat- erally with bilateral flexor plantar responses.

Laboratory evaluation included normal electrolytes, liver function tests, hemoglobin, and white blood cell count. Serum BUN and creatinine were normal for age. A urine metabolic screen was negative for organic acids. Peripheral blood buffy coat and rectal biopsy were negative for storage material, including ceroid lipofuscin. A head CT scan with and without contrast enhancement was unremarkable. An EEG performed during sleep and drowsiness was normal. Chromosomal analysis showed a normal female $46, X X$ chromosome complement with no apparent abnormalities of the $\mathrm{X}$ chromosome on prophase-banded preparations at the 750 band level.

\section{Family History}

Since the initial report of this kindred in 1971, there have been another 15 individuals (10 females and 5 males) born to its members. The pedigree is shown in Fig. 1. We have maintained the original pedigree numbers, adding new ones for individuals added

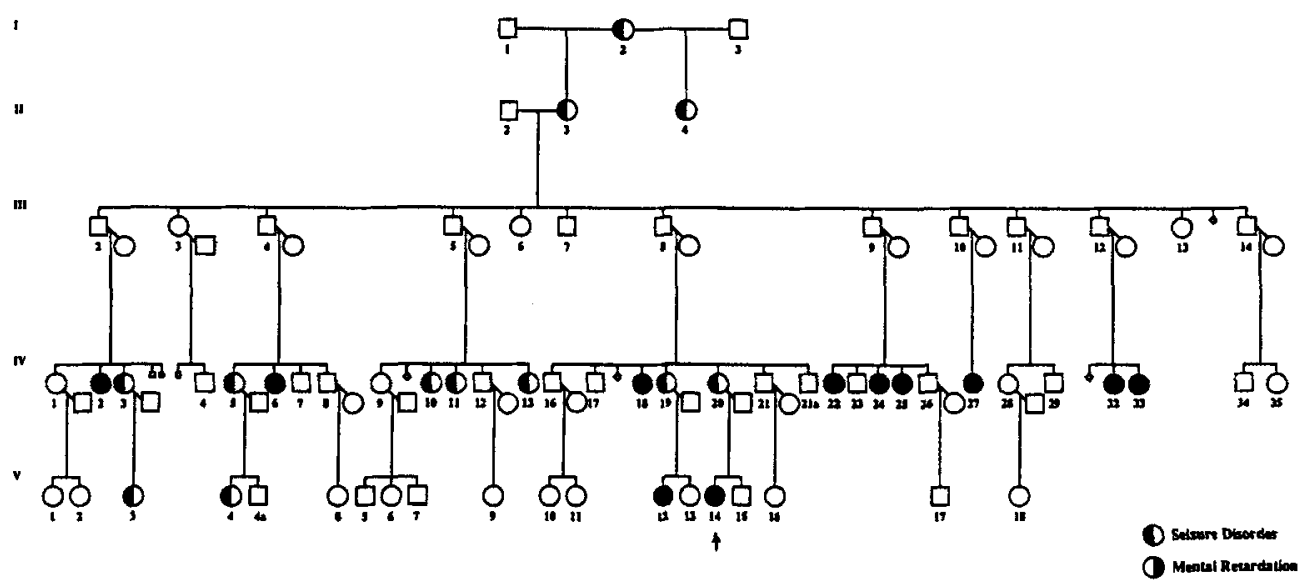

Fig. 1. Pedigree of the kindred, Small symbols indicate fetal wastage events of known, or unknown (diamond), sex. 
to the pedigree since 1971. Two of these new members of the kindred (V 14, V 12), including our patient, have seizures and loss of developmental milestones. In addition, a female previously reported as normal (IV 27) has since also developed seizures and loss of developmental milestones.

V 12 developed seizures at 7 months of age. At 28 months of age she began having increased frequency of seizures, occurring up to 10 times a day. At that time she also began to lose previously attained developmental skills.

IV 27 first developed seizures at 14 months of age during a febrile illness. At 31 months of age she developed increasing seizure frequency and loss of developmental milestones, and has been institutionalized since 5 years of age.

These histories are strikingly similar to those of the eight other females of the fourth generation with both seizures and mental retardation (IV 2, IV 6, IV 18, IV 22, IV 24, IV 25, IV 32, IV 33). All had onset of seizures within the first year of life and were generally felt to be attaining age-appropriate milestones until somewhere in the second to third year of life, when each developed increased frequency of seizure activity with subsequent loss of developmental milestones to a varying degree.

$\mathrm{V} \mathrm{13,} \mathrm{a} \mathrm{sibling} \mathrm{of} \mathrm{V} \mathrm{12,} \mathrm{and} \mathrm{whose} \mathrm{mother}$ has a seizure disorder, is at 4 years of age seizure-free and continuing to develop ageappropriate milestones. She is the only unaffected female born to a mother in generation IV with a seizure disorder. There are nine other unaffected females of the fifth generation; four born to unaffected mothers (V $1, \mathrm{~V} 2, \mathrm{~V} 6, \mathrm{~V} 18$ ), and five to unaffected fathers of the fourth generation ( $V 8, V 9$, $\mathrm{V} 10, \mathrm{~V} 11, \mathrm{~V} 16)$. All five males of the fifth generation are seizure-free and developing appropriately. Two are offspring of an unaffected mother (V 5 and V 7), two are offspring of affected mothers ( V 4a and V 15), and one is the offspring of an unaffected father (V 17).

The 12 unaffected males of the fourth generation have now produced a total of six offspring, including one normal male and five normal females. This is in contrast to the 30 living offspring of the ten unaffected males of the third generation, of whom 16 of 20 females have seizures with or without mental retardation. Thus transmission from unaffected males to their female offspring has not yet been seen from the fourth to the fifth generation as it had in the previous generation.

\section{Discussion}

The findings in this family are difficult to reconcile with any standard inheritance pattern. An autosomal dominant disorder with expression limited to females is one possibility. This hypothesis would not explain the slightly unusual sex ratios (not statistically significant) or the high frequency of affected daughters in generation IV $\left(X^{2}=5.44\right.$, $\mathrm{p}<0.02$ ). A dominant, $X$-linked trait with incomplete penetrance and sex-limited expression would explain the high frequency of affected daughters in generation IV and the lack of affected daughters of male sibs of affected females in generation IV (although only five are at risk). However, an $X$-linked, sex-limited trait would not be expected to affect such a high percentage of the daughters of affected females (but the numbers are not significant since the four affected are among only five at risk).

Germline (or chromosomal) imprinting provides an alternative explanation for some of the findings in this pedigree. It is a classic concept in genetics which was derived from studies of chromosomal elimination in Sciara - the set of chromosomes eliminated was always the paternal one and, thus, passage through the paternal germline must have provided information to, i.e. im- 
printed, the chromosomes (Crouse 1960). The $\mathrm{X}$ chromosome was the first example studied in mammals. It was found some time ago that in marsupials the paternal $X$ is preferentially inactivated (Cooper 1971), certainly in readily accessible tissues such as blood, and perhaps in many other tissues. The paternal $\mathrm{X}$ is preferentially inactivated in extraembryonic membranes in eutherians (Takagi \& Sasaki 1975). In fact, such germline imprinting has now been well demonstrated for many chromosomal regions in mice and explains the failure of parthenogenesis in mammals. It has been shown that gynogenetic embryos (2 female-derived chromosome sets; usually the result of artificial activation) had well-developed embryos, but the extra embryonic membranes were very poorly developed. On the other hand, androgenetic embryos (2 male-derived chromosome sets; created by nuclear transplantation), have poorly developed embryos but well-developed extra-embryonic membranes (Solter 1988). In fact, human hydatidiform moles are disorganized masses of extra embryonic membranes which result from the loss of the female pronucleus and the fusion of two male pronuclei from one or two spermatozoa (Lawler et al. 1982). Such results indicate that the mammalian embryo needs chromosome sets imprinted both through the ovary and through the testis for successful development. In fact, studies of mice suggest that a large part of the genome might need to be differentially imprinted (Cattanach \& Kirk 1985). Transgenes have also been used as a tool to study imprinting (Surani et al. 1988). There are many examples of a transgene's expression being different when transmitted by a male versus a female. There is also a case (Hadchouel et al. 1987) of a transgene's expression being permanently altered after one generation of imprinting.

Germline imprinting might have been a good explanation for the unusual pattern of expression in the pedigrees as reported earlier (Juberg \& Hellman 1971) but nor with the extension we provide. One could have postulated that the pattern of inheritance in this pedigree could be explained by a gene causing seizures in individual II 3 (and ignoring probably transmission fron? her mother) which was transmitted to 7 out of 9 of her sons, but which was imprinted in such a way that it was not expressed in these sons. It could further have been postulated that in the following generation, during spermatogenesis, the gene would have been imprinted in a de-repressed mode such that expression in the daughters of the transmitting males could now occur. However; one would have to argue that the imprinting did not continue in the same manner and that the gene continued to be expressed in the offspring of the following generation (which would also apply to transmission from generation I to II). If it was an X-linked gene, the excess of affected daughters to the generation III males would be explained.

Since a variably penetrant and expressed $\mathrm{X}$-linked trait with sex-limited expression might explain the findings in this pedigree, reasons for such sex-limited expression need to be considered. One hypothesis to explain sex-limited expression in this seizure disorder is by different neuroanatomical pathways between males and females. Sex-specific differences in neuronal networks have been described in adult brains of many species (Goy \& McEwen 1980, Arnold \& Gorski 1984, DeVries et al. 1984). Such sexspecific differences in the morphology of adult brains have usually been demonstrated to be secondary to differential exposure to gonadal steroids during critical perinatal periods (Gerall \& Ward 1966, von Saal \& Bronson 1978, Dohler et al. 1982) and are secondary to central nervous system aromatization of testosterone. Recently molecular markers for sex-specific differ- 
ences have been found which may provide clues as to the developmental basis of the differences in neuroanatomical structures (Tobet \& Fox 1989). It is possible that different arrangements of neurons and/or glia in males and females in this pedigree could result in different susceptibility to some seizure-promoting gene, although the known sex-hormone-related differences in the mammalian medial preoptic area and the spinal nucleus of the bulbocavernosus are unlikely candidates. Thus, a gene such as that causing autosomal dominant benign neonatal seizures (Cunniff et al. 1988) could interact with sex different neuronal networks to cause seizure disorders in the female but not in the male. The rapid onset of deterioration in these patients is reminiscent of that seen in Rett syndrome, which may be an X-linked trait - lethal in males and with females not reproducing (Opitz 1986). It is conceivable that our pedigree represents the inheritance of a less severely abnormal mutation at the same locus.

Asymmetry in the inheritance of epilepsy has long been known since children of affected women are more likely to have seizures than are those of affected men (Annegers et al. 1976, 1978). The inheritance of seizures and/or mental retardation from generation IV to generation $V$ of our pedigree shows this asymmetry. Analyses of data on families with epilepsy indicate that this asymmetry is not dependent on the etiology of the seizures, the seizure type, nor the use of anticonvulsants during pregnancy (Ottman et al. 1988). A recent genetic analysis (Ottman et al. 1988) concluded that the data provide evidence for a maternally transmitted influence on seizure susceptibility. Since the major known genetic element transmitted only maternally is that in the mitochondria (Giles et al. 1980), and possibly the centriole (Hall et al. 1989), it would seem possible that alterations in mitochondrial metabolism could affect susceptibility to seizures. Alternatively, a maternal effect due to in utero environment has not been precluded. However, in our pedigree, many female offspring of unaffected males have preferentially developed this disorder, but it appears that the following generation (generation $V$ ) provides a better fit for maternal inheritance. Overall, there is no evidence for a maternally transmitted influence of seizure susceptibility in our pedigree.

We conclude that a variably expressed and penetrant, X-linked and sex-limited trait best explains this pedigree of seizures with or without mental retardation. Sexual differentiation of the central nervous system may best explain the apparent sex-limitation of expression.

\section{Acknowledgements}

We thank Dr. R. Stan Blecher for comments and Mrs. Janice La Pointe for secretarial assistance.

Dedicated to the memory of the late Richard C. Juberg M.D., Ph.D. who first described this family.

\section{References}

Annegers, J. F., W. A. Hauser, L. R. Elvebark, V. E. Anderson \& L. T. Kurland (1976). Seizure disorders in offspring of parents with a history of seizures - a maternal-paternal difference? Epilepsia 17, 1-9.

Annegers, J. F., W. A. Hauser, L. R. Elveback, V. E. Anderson \& L. T. Kurland (1978). Congenital malformations and seizure disorders in the offspring of parents with epilepsy. Int. J. Epidemiol. 7, 24 I-247.

Arnold. A. P. \& R. A. Gorski (1984). Gonadal steroid induction of structural sex differences in the central nervous system. Ann. Rev. Neurosci. 7, 413-442.

Cattanach, B. M. \& M. Kirk (1985). Differential activity of maternally and paternally derived chromosome regions in mice. Nature 315, 496-498.

Cooper, D. W. (1971). Directed genetic change model for $\mathrm{X}$ chromosone inactivation in eutherian mammals. Nature 230, 292-294. 
Crouse, H. V. (1960). The controlling element in sex chromosome behaviour in Sciara. Genetics 45, 1429-1443.

Cuniff, C., N. Weidlin \& K. L. Jones (1988). Autosomal dominant benign neonatal seizures. Am. J. Med. Genet. 30, 963-966.

DeVries, G. J., J. P. C. Bruin, H. B. M. Uylings \& M. A. Corner (eds.) (1984). Sex differences in the brain: the relationship between structure and function. Prog. Brain. Res. 61, 1-508.

Dohler, K. D., A. Coquelin, F. Davis, M. Hines, J. E. Shryne \& R. A. Gorski (1982). Differentiation of the sexually dimorphic nucleus in the preoptic area of the rat brain is determined by the perinatal hormone environment. Neurosci. Lett. 33, 295-298.

Erickson, R. P. (1985). Chromosomal imprinting and the parent transmission specific variation in expressivity of Huntington's disease. $\mathrm{Am} . \mathrm{J}$ .Hum. Genet. 37, 827-829.

Gerall, A. A. \& L. L. Ward (1966). Effects of prenatal exogenous androgen on the sexual behaviour of the female albino rat. J. Comp. Physiol. Psychol. 62, 370-375.

Giles, R. E., H. Blanc, H. M. Cann \& L. C. Wallace (1980). Maternal inheritance of human mitochondrial DNA. Proc. Natl. Acad. Sci. U.S.A. 77, 6715-6719.

Goy, R. W. \& B. S. McEwen (ed.) (1980). Sexual differentiation of the brain. Cambridge, MIT Press, pp. 1-158.

Hadchouel, M., H. Farza, D. Simon, P. Tiollais \& C. Pourcel (1987). Maternal inhibition of hepatitis B surface antigen gene expression in transgenic mice correlates with de novo methylation. Nature 329, 454-456.

Hall, J. L., Z. Raminis \& D. S. Luck (1989). Basal body/centriolar DNA: molecular genetic studies in chlamydomonas. Cell 59, 121-132.

Juberg, R. C. \& C. D. Hellman (1971). A new familial form of convulsive disorder and mental retardation limited to females. J. Pediatr. 79, 726-732.

Lawler, S. D., S. Porey, R. A. Fisher \& V. J. Pickthal (1982). Genetic studies on hydatid- iform moles, II. The origin of complete moles. Ann. Hum. Genet. 46, 209-222.

Leppert, M., V. E. Anderson, T. Quattlebaum, D. Stauffer, P. O'Connell, Y. Nakamura, J.-M. Lalouel \& R. White (1989). Benign familial neonatal convulsions linked to markers on chromosome 20. Nature 337, 647-648.

Monk, M. (1988). Genomic imprinting. Genes Devel. 2, 921-925.

Morris, C., J. C. Palumbos \& J. C. Carey (1987). Delineation of the male phenotype in craniofrontonasal syndrome. Am. J. Med. Genet. 27, 623-631.

Opitz, J. M. (1986). Editorial Comment: Rett syndrome: some comments on terminology and diagnosis. Am. J. Med. Genet. 24, 27-37.

Ottman, R., J. F. Annegers, W. A. Hauser \& L. T. Kurland (1988). Higher risk of seizures in offspring of mothers than of fathers with epilepsy. Ain. J. Hum. Genet. 43, 257-264.

Solter, D. (1988). Differential imprinting and expression of paternal and maternal genomes. Ann. Rev. Genet. 22, 127-146.

Surani, M. A., W. Reik \& N. D. Allen (1988). Transgenes as molecular probes for genomic imprinting. Trends Genet. 4, 59-62.

Takagi, N. \& M. Sasaki (1975). Preferential inactivation of the paternally derived X-chromosome in the extraembryonic membranes of the mouse. Nature 256, 640-642.

Tobet, S. A. \& T. O. Fox (1989). Sex- and hormone-dependent antigen immunoreactivity in developing rat hypothalamus. Proc. Natl. Acad. Sci. U.S.A. 86, 382-386.

von Saal, F. S. \& F. H. Bronson (1978). In utero proximity of female mouse fetuses to males: effect on reproductive performance during later life. Biol. Reprod. 19, 842-853.

\section{Address:}

Robert P. Erickson, M.D.

Director, Pediatric Genetics

University of Michigan School of Medicine

DII09 Medical Professional Building

Box 0718

Ann Arbor, MI 48109-0718, USA 